\title{
Effect of performance based financing home visiting on the use of modern methods of contraception in the kumbo east health district, Cameroon
}

Thomas Obinchemti Egbe ${ }^{1 *}$ (D) Julius Atashili ${ }^{2}$ Emmanuella Talla ${ }^{3}$ and Mary Bih Suh Atanga ${ }^{4}$

\begin{abstract}
Background: The use of modern methods of contraception (MMC) as defined by the World Health Organization still remains a challenge in most of Sub-Saharan Africa. Performance Based Financing (PBF) home visit was introduced in 2012 to increase the use of those modern methods in the Kumbo East Health District (KEHD), Cameroon.

We determined the utilization rates of MMC in areas in the KEHD with PBF home visits compared with those areas with no home visits.

Methods: This was a cross sectional study carried out in the KEHD during the period February 1 to May 31, 2015. A multistage cluster sampling method was used to recruit 262 and 221 women aged 15-49 years in the intervention and nonintervention health areas, respectively. A structured, closed ended questionnaire was used.

Results: The average age of women was similar in both groups 30.40 (SD 8.57); median 30 years in the intervention group and 30.49 (SD 7.84); median 30 years in controls. Most participants in the intervention health area (60.3\%) used modern methods of contraception compared to $46.6 \%$ of those in the control group (aOR: $1.75 \%$; $95 \%$ Cl: 1.212.53) and the most commonly used MMC was medroxyprogesterone in the intervention group and condoms in the control area.
\end{abstract}

Conclusion: Utilization of MMC was significantly higher in the area with PBF home visits than in areas without that service. While this indicates that the intervention has benefit, there may be other contributing factors.

Keywords: Performance based financing, Utilization, Modern methods of contraception, Women of childbearing age, Medroxyprogesterone acetate

Abbreviations: IHA, Intenvention health areas; KEHD, Kumbo east health district; MMC, Modern methods of contraception; NIHA, Non intervention health areas; PBF, Performance based financing; STD, Sexually transmitted diseases

\footnotetext{
*Correspondence: toegbe@gmail.com; tom.egbe@outloot.com;

obinchemti@yahoo.com

${ }^{1}$ Department of Obstetrics and Gynecology, Faculty of Health Sciences,

University of Buea, P.O. Box 63, Buea, Cameroon

Full list of author information is available at the end of the article
} 


\section{Background}

Over half of the 278,000 maternal deaths in 2010 occurred in Sub-Saharan Africa $[1,2]$. Rates of unintended pregnancy in Cameroon in 2013 totaled 490,000 and was attributable in large part to low utilization of contraception, particularly modern methods [3-6]. These latter include combined hormonal contraceptives, progestin-only pills, contraceptive injections, intrauterine devices, implants, male and female condoms and permanent contraception for both men and women. On the other hand, non-modern methods (behavior methods) include fertility awareness and coitus interruptus [7]. Progress has been made in the use of contraception in Sub Saharan Africa overall and in Cameroon in particular. However, in 2011 only $23.4 \%$ of the population of Cameroon used any contraception and $14.1 \%$ used MMC [5].

In order to improve utilization of contraception, a performance based financing $[\mathrm{PBF}]$ pilot project was introduced in the Kumbo East Health District (KEHD) in 2012. The KEHD has a surface area of about $1,087 \mathrm{~km}^{2}, 20$ health areas and a population of 179789 inhabitants of which 43 689 are women of child bearing age. The KEHD has a hilly terrain with towns located on hills and valleys and there are fast flowing streams which render the district inaccessible all year round. Local community radios such as the Bui Community radio, Helenkris radio, City Community radio and radio Evangelium broadcast in the district, but many women in the study groups are farmers and do not have time to listen to radio-broadcast public health messages.

For this project, contracts were signed and nurses were trained to provide women education in their homes about contraception and prevention of sexually transmitted infections. They were taught about the reproductive cycle, mechanism of action for each of the methods. The training was designed to enable them to tell women about each method, including its effectiveness, medical eligibility, cost side effects and safety while appreciating the woman's preference, fertility desires and risks of STDs [8, 9].

The women then returned to their homes, in the intervention areas, in the District and went from house to house to educate women about their STD risks and their options and to refer them to the nearest hospital for counseling and method initiation [9].

In the Kumbo East health district, condoms are free and available at the pro-pharmacies in Government health facilities while the other methods are also subsidized at the Government health facilities. The average cost of contraceptives was 2.63 USD; range 0.17-8.62 USD. The majority of participants used male condoms and the injectable that cost 0.17 USD, respectively. The monthly income of the population ranged between 21.83 and 94.54 USD [10].

The aim of this study was to estimate the effect of home visits on the use of modern methods of contraception by women of childbearing age in the Kumbo East Health District, Cameroon by comparing the rates of use in KEHD in areas served by home visits compared to those areas without home visits. The distances between health facilities in both study groups were similar.

\section{Methods}

This cross sectional comparative study was approved by Faculty of Health Science Institute Review Board of the University of Buea, Cameroon and the Regional Delegation of Public Health of the North West. Women aged 15-20 years of age signed assent forms and agreement was obtained from their guardian/parent; women age 21-49 signed informed consents.

A 27-item questionnaire was developed and beta-tested on 10 sexually active women age $15-49$, for comprehension and content validity. The questionnaire was designed to take $15 \mathrm{~min}$ to administer and covered the women's demographics (age, education, occupation, marital status, number of children and religion) and her knowledge of contraceptive options and her personal contraceptive use.

Women eligible to participate in the study had to live in the KEHD for at least twelve consecutive months and have been educated on the MMC; speak English or pidgin; be willing to give informed consent; and to be at-risk of pregnancy, defined as not being pregnant at enrollment, being fertile and of reproductive age (15-49 years of age). In addition, they needed to have had sex in the past month or be planning on having sex in the next month with at least one fertile male partner and not consistently using any birth control. We defined inconsistent use of birth control as not having used contraception during every sexual encounter within 3 months before enrollment. The surveyors were trained on all aspects of the study, including exclusion criteria.

\section{Sample size determination}

The sample size was calculated using the sample size formula for two proportions and confirmed with Epi info version 7 . Based on the fact that we used cluster sampling in this study, a design effect of 2 was employed [11].

$\mathrm{N}=\operatorname{DEFF} X 2 \frac{|Z c r i t \sqrt{2 p(1-p)+Z p w r \sqrt{P 1(1-P 1)+P 2(1-P 2)}}| 2}{\mu^{2}}$

Where p1 and p2 are pre-study estimates of the two proportions to be compared, $\mathrm{D}=|\mathrm{p} 1-\mathrm{p} 2|$ or minimum expected difference, $=(+) / 2 \mathrm{~N}$. was the total sample size (sum of the sizes of both comparison groups), was the desired significance criterion and was the desired statistical power. The values used for the calculation included a statistical power of $0.80,=0.842$, Significance criterion of $0.05,=1.960$ and DEFF $=2$ was the design effect [12]. The p1 $=0.2 \%$ was the proportion of women using modern methods of contraception in the KEHD in 2011 [13]. p2 = 
$7.1 \%$ was an assumption. We assumed that through home visits the contraceptive use would have increased by $6.9 \%$ as was observed in Rwanda [14]. = 3.6, D =6.9. This gave a sample size $\mathrm{N}$ of 460 .

Assuming a $20 \%$ non-response rate, we therefore had a sample size of 552 (276 in each study group). After data collection, the response rate was $87.5 \%$ therefore giving a sample size of 483 participants. From this sample size 262 women were recruited in the intervention health areas (IHA-home visits) and 221 participants were enrolled in the nonintervention health areas (NIHA-no-home visits).

\section{Sampling method}

We used multistage cluster sampling method where a list of all the 20 health areas and their population of women of childbearing age was collected from the KEHD. The number of households per cluster was calculated from this population by dividing the total population by 6 (average size of a household in Cameroon was 6 persons per household) [15].

Next probability proportionate to size method was used to select the different clusters (communities) within the health areas. The representative sample of health areas within the district was done by calculating the sampling interval (the total number of households divided by the total number of clusters needed). A total of 25 clusters each was required for both the health areas implementing home visits and those with no home visits [13]. A random number between one and the sampling interval was chosen to represent our reference point. This random value was then added to the sampling interval to get the cluster positions. This was done continuously until we obtained the total number of clusters (communities) needed (25 clusters per group) (Table 1).
Finally, a simple random sampling of the groups was selected by balloting among the clusters in order to identify the communities to be used for the study in each health area. Then an equal number of participants (first 11 women per cluster or community) was selected and one woman of childbearing age was interviewed per household. Also, we had a briefing meeting with health personnel already in the pilot project at the beginning of our study to ensure that those staff also understood clearly the objectives of our study.

We entered data into Microsoft Excel and analyzed with the statistical package STATA. The analysis focused on the impact of home visit involving family planning counseling, without receipt of contraception, and no home visits. In computing the socio-demographic characteristics of study participants, measures of central tendencies: mean and standard deviation were used while frequencies were used to compute level of education, religion, marital status, occupation and number of children. The Chi squared, student $t$-test and Anova were used to test for significant associations when appropriate. Binary logistic regression was used to measure the level of association and multiple logistic regressions were computed to control for confounders. Statistical significance was set at $p<0.05$.

\section{Results}

Data were collected from February 1 to May 31, 2015. Selected homes were visited and the questionnaire was administered to eligible participants who consented to be part in the study. Data was collected on traditional holidays, market days and after $4 \mathrm{pm}$ when women were at home after their daily activities. We could not rely on telephone numbers because majority of our patients did not have phones and the telephone network was usually difficult to go through During that period 552 participants

Table 1 Cluster Characteristics

\begin{tabular}{|c|c|c|c|c|c|c|c|c|c|c|c|}
\hline \multicolumn{5}{|c|}{ Health areas with Home visit intervention } & \multicolumn{7}{|c|}{ Health areas with no home visit intervention } \\
\hline $\begin{array}{l}\text { Health } \\
\text { area }\end{array}$ & $\begin{array}{l}\text { No. of women } \\
\text { age 15-49 } \\
\text { years }\end{array}$ & $\begin{array}{l}\text { No. of } \\
\text { households }\end{array}$ & cumulative & $\begin{array}{l}\text { No. of } \\
\text { clusters per } \\
\text { health area }\end{array}$ & $\begin{array}{l}\text { percentage } \\
\text { particiants } \\
\text { per cluster }\end{array}$ & community & $\begin{array}{l}\text { No. of women } \\
\text { age } 15-49 \\
\text { years }\end{array}$ & $\begin{array}{l}\text { No. of } \\
\text { households }\end{array}$ & cumulative & $\begin{array}{l}\text { \# of } \\
\text { cluster }\end{array}$ & $\begin{array}{l}\text { percentage } \\
\text { participants } \\
\text { per cluster }\end{array}$ \\
\hline Shisong & 4396 & 733 & 733 & 4 & $16 \%$ & Mbah & 1690 & 282 & 282 & 1 & $4 \%$ \\
\hline Jakiri CMA & 2725 & 454 & 1187 & 3 & $12 \%$ & Sop & 3184 & 531 & 813 & 4 & $16 \%$ \\
\hline Jakiri IHC & 2913 & 486 & 1673 & 3 & $12 \%$ & Ngorin & 1035 & 173 & 985 & 2 & $8 \%$ \\
\hline Mbam & 3306 & 551 & 2224 & 3 & $12 \%$ & Mbonso & 1697 & 283 & 1268 & 2 & $8 \%$ \\
\hline Mbokam & 1323 & 221 & 2444 & 2 & $8 \%$ & Verkovi & 3307 & 551 & 1819 & 4 & $16 \%$ \\
\hline Ndzeng & 1912 & 319 & 2763 & 2 & $8 \%$ & Wvem & 1016 & 169 & 1989 & 1 & $4 \%$ \\
\hline Nkar & 1348 & 225 & 2988 & 1 & $4 \%$ & Nkwaso & 1408 & 235 & 2223 & 3 & $12 \%$ \\
\hline Lip & 607 & 101 & 3089 & 1 & $4 \%$ & Wainamah & 1433 & 239 & 2462 & 3 & $12 \%$ \\
\hline Tartum & 3420 & 570 & 3659 & 3 & $12 \%$ & Mbiame & 5066 & 844 & 3306 & 5 & $20 \%$ \\
\hline Ngendzen & 411 & 69 & 3727 & 1 & $4 \%$ & & & & & & \\
\hline Wasiber & 1492 & 249 & 397 & 2 & $8 \%$ & & & & & & \\
\hline Total & 23853 & 3976 & & & $100 \%$ & & & 3306 & & & $100 \%$ \\
\hline
\end{tabular}


were enrolled, but only 483 (87.5\%) were interviewed and completed the survey. 262 were studied in health areas with home visits and 221 women in health areas with no home visits (Fig. 1). The mean age of women in each of the groups was similar 30.40 (SD 8.57); median 30 years; range 15-48 years versus 30.49 (SD 7.84); median 30 years; range $16-49$ years $(p=0.90)$ (Table 1$)$. Over half $(52 \%)$ of study participants were Catholics $(p<0.03)$ and $44.7 \%$ had secondary education or less $(p<0.06)$. There were no statistical differences in participant characteristics between the intervention and no intervention groups, including marital status $(p<0.25)$, employment status $(p<0.78)$ and having parity of 2 or more children $(p=0.54)$ (Table 2$)$.

Nearly 6 out of $10,(59.92 \%)$ of the participants in health areas with home visits reported current use of MMC compared to $46.61 \%$ participants in the control group used MMC, $(p=0.003)$. The odds ratio was 0.7 (95\% CI, 1.19-2.46.). After adjusting for differences in regions, the aOR was 1.8 (95\% CI, 1.21-2.53).

In both areas, the most frequently used methods were behavioral methods, but their use was much less common in the intervention group (25.9 vs $38.1 \%)$. The most common MMC used in the intervention area was injections $(24.1 \%)$ whereas, the male condom was the most commonly used MMC in the nonintervention area (25.8 \%). In the intervention group, use of other MMC was significantly more frequent; pill use was higher than implant use (7.7 vs $1.8 \%$ ) (Table 3 ).

\section{Discussion}

Our study has shown that MMC use was more common in areas served by PBF home visitors. The importance of PBF home visits to our study population stems from the fact that most women are farmers and are not readily at home to obtain information about MMC from local radio stations. This is consistent with other studies that have proved that use of social workers increase the use of MMC [16]. Mercer et al. in Bangladesh, did find that home visits increased the use of injectables from 5 to $10 \%$ [17], as well as USAID report which found a significant increase in the use of injectables in programs that implemented home delivery of MMC [18]. The fundamental difference between our study and that in Bangladesh was that field workers in rural Bangladesh distributed injectables to women at home while in this study (KEHD) women had to go to health facilities to get the MMC.

However, our findings differ from a Rwandan study by Skile and colleagues; they found that home visit did not impact the use of MMC. It is possible that this may be due to the extreme equity gap seen between the two populations studied [14].

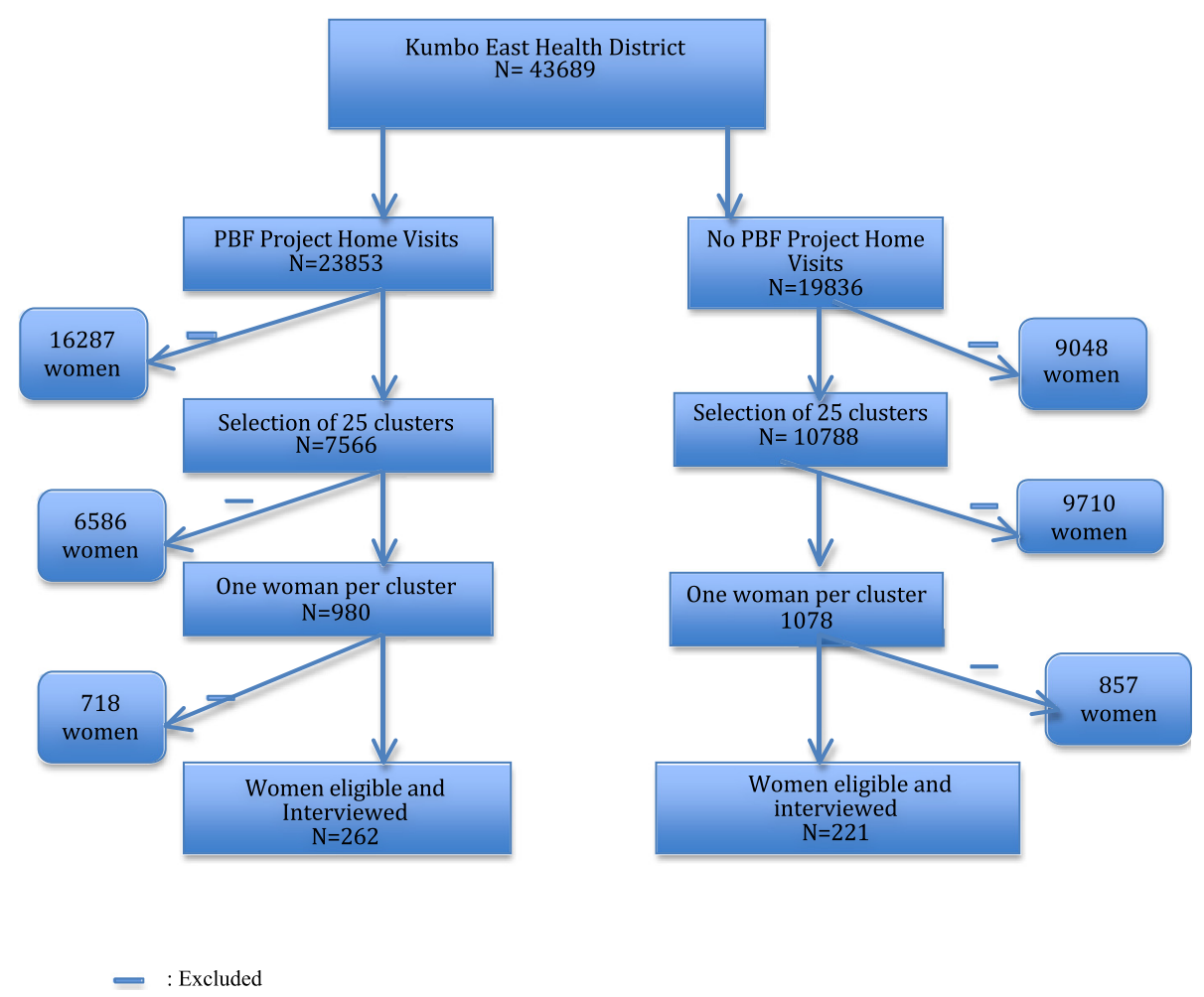

Fig. 1 Consort diagram 
Table 2 Socio-demographic characteristics of study population

\begin{tabular}{|c|c|c|c|c|}
\hline \multirow{2}{*}{\multicolumn{2}{|c|}{ Variable }} & \multicolumn{2}{|c|}{ Intervention (home visit) } & \multirow[b]{2}{*}{$P$-value } \\
\hline & & No $(N=221)$ & Yes $(N=262)$ & \\
\hline \multicolumn{5}{|c|}{ Age (years) } \\
\hline & Age $( \pm S D)$ & $30.40 \pm 8.57$ & $30.49 \pm 7.84$ & 0.90 \\
\hline \multicolumn{5}{|c|}{ Education (N, \%) } \\
\hline & None & $14(6.33 \%)$ & 7 (2.67 \%) & 0.06 \\
\hline & Primary level & $94(42.53 \%)$ & $98(37.40 \%)$ & \\
\hline & Secondary level & $91(41.18 \%)$ & $117(44.66 \%)$ & \\
\hline & Tertiary level & $22(9.95 \%)$ & $40(15.27 \%)$ & \\
\hline \multicolumn{5}{|c|}{ Religion (N, \%) } \\
\hline & Catholic & $116(52.49 \%)$ & $131(50.00 \%)$ & 0.03 \\
\hline & Baptist & $35(15.84 \%)$ & $22(8.40 \%)$ & \\
\hline & Presbyterian & $32(14.48 \%)$ & $53(20.23 \%)$ & \\
\hline & Pentecostal & $0 \%$ & $3(1.15 \%)$ & \\
\hline & Muslim & $38(17.19 \%)$ & $53(20.23 \%)$ & \\
\hline \multicolumn{5}{|c|}{ Marital status (N,\%) } \\
\hline & Single & $39(17.65 \%)$ & $48(18.32 \%)$ & 0.25 \\
\hline & Married & $164(74.21 \%)$ & $195(74.43 \%)$ & \\
\hline & separated/divorced & $15(6.79 \%)$ & $10(3.82 \%)$ & \\
\hline & Widowed & $3(1.36 \%)$ & $9(3.44 \%)$ & \\
\hline \multicolumn{5}{|c|}{ Occupation (N, \%) } \\
\hline & Unemployed & $80(36.20 \%)$ & $98(37.40 \%)$ & 0.78 \\
\hline & Employed & $141(63.8 \%)$ & $164(62.60 \%)$ & \\
\hline \multicolumn{5}{|c|}{ Number of children ( $\mathrm{N}, \%)$} \\
\hline & $0-2$ & 95 (42.99 \%) & 126 (57.01\%) & 0.54 \\
\hline & $3>5$ & $120(45.80 \%)$ & $142(54.20 \%)$ & \\
\hline
\end{tabular}

Melnick et al. in the USA did not find an association between the method of contraception used and home visits [19]. This difference could possibly be because our study recruited participants who were interested in delaying pregnancy using specific methods. In addition, we found that women in health areas with home visits were 3.6 times more likely to use implants compared to those without home visits. This was not consistent with the findings of Egede JO et al. in Nigeria who reported that the most commonly used forms of modern contraception were the barrier method (male condoms, $8.2 \%$, the oral contraceptive pill $3.0 \%$, injectables $2.5 \%$, and the intrauterine contraceptive device $2.0 \%$ [20].

The use of MMC is responsible for improving maternal and infant health outcomes [7]. A global review of 172 studies by Ahmed and colleagues in 2012 calculated that the use of MMC prevented 272,040 maternal deaths, a $44 \%$ reduction without which maternal deaths would have been 1.8 times higher than 2008 totals [21]. Cameroon has a maternal mortality rate of 680 women per 100,000 live births from pregnancy [6]. If all women with unmet needs of contraception were to use $\mathrm{MMC}$, it is estimated that 373,000 unintended pregnancies could be prevented, and therefore, unplanned births, abortions and miscarriages could be reduced by $3 / 4$; maternal deaths would be reduced by 1,300 and infant deaths by 13,000 annually [6]. This would substantiate many of the older millennium development goals.

Table 3 Distribution of current use of MMC

\begin{tabular}{|c|c|c|c|c|c|c|c|c|}
\hline \multicolumn{3}{|c|}{ intervention (home visit) } & \multirow[b]{2}{*}{$p$ value } & \multirow[b]{2}{*}{ OR } & \multirow[b]{2}{*}{95 \% Cl } & \multirow[b]{2}{*}{$\mathrm{aOR}$} & \multirow[b]{2}{*}{$p$ value } & \multirow[b]{2}{*}{95 \% Cl } \\
\hline Variable & no & yes & & & & & & \\
\hline \multicolumn{9}{|c|}{ Current use of MMC (N, \%) } \\
\hline No & 118/221 (53.39 \%) & 105/262 (40.08 \%) & & & & & & \\
\hline Yes & 103/221 (46.61 \%) & 157/262 (59.92 \%) & 0.003 & 1.71 & $1.19-2.46$ & 1.75 & 0.003 & $1.21-2.53$ \\
\hline \multicolumn{9}{|c|}{ Current use of MMC by method ( $N, \%)$} \\
\hline Natural & 84/221 (38.01 \%) & 68/262 (25.95\%) & & & & & & \\
\hline Implant & $4 / 221(1.81 \%)$ & $12 / 262(4.58 \%)$ & & 3.71 & $1.14-12.01$ & 3.56 & 0.029 & $1.08-11.73$ \\
\hline IUD & $7221(3.17 \%)$ & 9/262 (3.44 \%) & & 1.59 & $0.56-4.49$ & 2.01 & 0.382 & $0.69-5.84$ \\
\hline \multicolumn{9}{|l|}{ Tubal } \\
\hline ligation & $1 / 221(0.45 \%$ & 2/262 (0.76 \%) & & 2.47 & $0.22-27.83$ & 2.82 & 0.464 & $0.23-34.77$ \\
\hline Injectable & 17/221 (7.69 \%) & 63/262 (24.05\%) & & 4.58 & $2.45-8.54$ & 4.95 & $<0.001$ & $2.63-9.34$ \\
\hline Pills & 17/221 (7.69 \%) & 26/262 (9.92 \%) & & 1.89 & $0.95-3.77$ & 2.04 & 0.071 & $1.01-9.34$ \\
\hline \multicolumn{9}{|l|}{ male } \\
\hline condoms & 57/221 (25.79 \%) & 46/262 (17.56 \%) & & 1.00 & $0.60-1.64$ & 1.02 & 0.99 & $0.61-1.70$ \\
\hline None & $34 / 221(15.38 \%)$ & $36262(13.74 \%)$ & $<0.001$ & 1.31 & $0.74-2.31$ & 1.45 & 0.354 & $0.82-2.59$ \\
\hline \multicolumn{9}{|c|}{ Frequency of use of $\mathrm{MMC}(\mathrm{N}, \%)$} \\
\hline Frequent & 47/103 (45.63 \%) & $81 / 157(51.59 \%)$ & & & & & & \\
\hline Infrequent & 56/103 (54.37 \%) & 76/157 (48.41 \%) & 0.35 & & & & & \\
\hline
\end{tabular}

$a O R$ adjusted odds ratio, $O R$ odds ratio, $\mathrm{Cl}$ Confidence Intervals 
Our study was based on a self-reported use of MMC, therefore they may be a risk of recall bias and reporting bias. An additional limitation is potential selection bias. Because we could not obtain personal information on participants until they consented to participate in the study, we have no information on those who refused to participate, nor do we have information on potential participants who were difficult to reach.

Other confounders may have impacted on our findings. Some of the strategies from the intervention pilot project may have spread into the control area. Some women that were interviewed in the areas not served by the pilot project said they had heard of MMC from home-based counselors. Similarly, HIV prevention campaigns conducted in all health areas promoted both male and female condoms and may also have increased the use of the modern method in the control area. However, these confounders would have decreased the impact of the pilot project. The fact that we observed a $70 \%$ higher utilization of MMC in the PBF pilot project despite these confounders supports the effectiveness of this initiative. Extension of this project into other regions may well yield important benefits to the health of reproductive age women and their families. Future research that explores the involvement of religious leaders in these regions may identify ways to magnify these benefits.

\section{Conclusion}

Utilization of MMC was significantly (1.7 times) higher in the area with PBF home visits than in areas without that service. While this indicates that the intervention has benefit, there may be other contributing factors.

\section{Acknowledgements}

We thank the health team of the KEHD specifically the District Medical Officer (Dr. Leuteu Petmi Landry) for being very supportive during proposal development and data collection. We also thank the women who comprised our study population in the KEHD for sharing their private experiences on sexuality and contraception. Special thanks to the Victory Outreach Ministries for their support. We also thank Dr Julius Che Tita for proof reading the manuscript. His suggestions have been valuable.

\section{Funding}

No funding has been obtained from any source to carry out this study.

\section{Available of data and material}

"The dataset(s) supporting the conclusions of this article is (are) could be obtained from the authors on request by the editors."

\section{Authors' contributions}

TOE and TE and MSBA designed the study. Data collection was done by TE. $T O E, J A$ and TE conducted analysis and interpretation of study data. TOE and TE drafted the manuscript. All authors reviewed, edited and approved the final version of the manuscript.

\section{Competing interests}

The authors declare that they have no competing interests.

\section{Consent for publication}

Written informed consent was obtained from the patient for publication of data. A copy of the written consent is available for review by the Editor-in-Chief of this journal."

\section{Ethics approval and consent to participate}

Ethical clearance was obtained from the Institutiona Review Board of the Faculty of Health Sciences, University of Buea. Autorisation was obtained from the Regional Delegation of Public Health, North West Region, Cameroon and the Chief Medical officers of the Health Institutions in the KEHD.

\section{Author details}

${ }^{1}$ Department of Obstetrics and Gynecology, Faculty of Health Sciences, University of Buea, P.O. Box 63, Buea, Cameroon. ${ }^{2}$ Department of Public Health, Faculty of Health Sciences, University of Buea, P.O.Box 63, Buea, Cameroon. ${ }^{3}$ Delegation of Public Health, North West Region, Cameroon. ${ }^{4}$ Department of Nursing and Midwifery, Faculty of Health Sciences, University of Bamenda, Bambili, Cameroon.

Received: 8 December 2015 Accepted: 11 August 2016

Published online: 31 August 2016

\section{References}

1. AfricaFiles | Sub-Saharan Africa's maternal death rate down 41 per cent [http://www.africafiles.org/article.asp?ID=26434] Accessed 17 May 2012.

2. Maternal Mortality in Sub-Saharan Africa: Steps Towards Millennium Developmental Goals - viewcontent.cgi [http://digitalcommons.hsc.unt.edu/ cgi/viewcontent.cgi?article=1764\&context=theses] by IU Eghieye -2014 .

3. Stephenson R, Baschieri A, Clements S, Hennink M, Madise N. Contextual influences on modern contraceptive use in sub-Saharan Africa. Am J Public Health. 2007;97:1233-40.

4. Gakidou E, Vayena E. Use of modern contraception by the poor is falling behind. PLoS Med. 2007:4:e31.

5. Kelodjouea S. Trends and Determinants of Unmet Need for Family Planning in Cameroon: The Role of Socio-Cultural Context. Sociology. 2015;5:39-52.

6. Vlassoff M, Beninguisse G, Kamgaing F, Jerman J and Zinvi F. The Costs and Benefits of Reproductive Health Interventions in Cameroon. PAA Annu Meet Boston MA 2014:20. [http://www.paa2014.princeton.edu/papers/142862].

7. WHO | Family planning/Contraception [http://www.who.int/mediacentre/ factsheets/fs351/en/].

8. Contraception | Unintended Pregnancy | Reproductive Health | CDC [http:// www.cdc.gov/reproductivehealth/contraception.htm].

9. Performance Based Financing Procedure Manual North West Region of Cameroon. 2012.

10. Cameroon map of Map of Cameroon: Average Monthly Rural Income by Region [2010 Data] by Province - TargetMap [www.targetmap.com/viewer aspx?reportld=12773].

11. Reproductive Health Assessment Toolkit for Conflict-Affected Women - chapter1_introduction_tag508.pdf [http://www.cdc.gov/reproductivehealth/global/ tools/docs/pdf/chapter-1_introduction_tag508.pdf].

12. Eng J. Sample size estimation: how many individuals should be studied? Radiology. 2003;227:309-13.

13. Kumbo East Health Report

14. Skiles MP, Curtis SL, Basinga P, Angeles G. An equity analysis of performancebased financing in Rwanda: are services reaching the poorest women? Health Policy Plan. 2013;28:825-37.

15. Report - IMC Cameroon - International Medical Corps. internationalmedicalcorps. org/document.doc?id=88.

16. Kincaid DL. Social networks, ideation, and contraceptive behavior in Bangladesh: a longitudinal analysis. Soc Sci Med. 2000;50:215-31.

17. Mercer A, Ashraf A, Huq NL, Haseen F, Uddin AHN, Reza M. Use of family planning services in the transition to a static clinic system in Bangladesh: 1998-2002. Int Fam Plan Perspect. 2005;31:115-23.

18. USAID Report; Home delivery of Injectable contraception - Google Scholar [http://pdf.usaid.gov/pdf_docs/PDACL615].

19. Melnick A: Nurse family partnership contraceptive study. In 141st APHA Annual Meeting and Exposition (November 2-November 6, 2013). APHA; 2013.

20. Egede JO, Onoh RC, Umeora OUJ, lyoke CA, Dimejesi IBO, Lawani LO. Contraceptive prevalence and preference in a cohort of south-east Nigerian women. Patient Prefer Adherence. 2015;9:707-14.

21. Ahmed S, Li Q, Liu L, Tsui AO. Maternal deaths averted by contraceptive use: an analysis of 172 countries. Lancet. 2012;380:111-25. 